\title{
Article \\ In Vivo Effects of Two In-Office Vital Tooth Bleaching Systems on Enamel Permeability
}

\author{
Angelica Bertacci ${ }^{1, *}$, Gianfranco Ulian ${ }^{2} \oplus$, Daniele Moro ${ }^{2} \oplus$, Stefano Chersoni ${ }^{1}$ and Giovanni Valdrè ${ }^{2, *}$ \\ 1 Department of Biomedical and Neuromotor Sciences (DiBiNeM), School of Dentistry, University of Bologna, \\ 40125 Bologna, Italy; stefano.chersoni@unibo.it \\ 2 Department of Biological, Geological, and Environmental Sciences, University of Bologna, \\ 40126 Bologna, Italy; gianfranco.ulian2@unibo.it (G.U.); daniele.moro@unibo.it (D.M.) \\ * Correspondence: angelica.bertacci3@unibo.it (A.B.); giovanni.valdre@unibo.it (G.V.)
}

Citation: Bertacci, A.; Ulian, G.; Moro, D.; Chersoni, S.; Valdrè, G. In Vivo Effects of Two In-Office Vital Tooth Bleaching Systems on Enamel Permeability. J. Compos. Sci. 2021, 5, 98. https://doi.org/10.3390/ jcs5040098

Academic Editor:

Francesco Tornabene

Received: 20 March 2021

Accepted: 2 April 2021

Published: 4 April 2021

Publisher's Note: MDPI stays neutral with regard to jurisdictional claims in published maps and institutional affiliations.

Copyright: (c) 2021 by the authors. Licensee MDPI, Basel, Switzerland. This article is an open access article distributed under the terms and conditions of the Creative Commons Attribution (CC BY) license (https:// creativecommons.org/licenses/by/ $4.0 /)$.

\begin{abstract}
Tooth bleaching is a common treatment for the amelioration of the aesthetic of discoloured teeth. In this context, there are two common approaches that employ concentrated solutions (30-40 wt.\%) of either hydrogen peroxide or carbamide peroxide as bleaching agents. However, there is an ongoing debate on the possible adverse effects of these different treatments on tooth health, such as variation of the enamel structure, surface morphology, and chemistry, which also affect tooth sensitivity. In the present work, a study on the effect of the two bleaching agents, a $35 \mathrm{wt}$.\% solution of hydrogen peroxide and a $30 \mathrm{wt} . \%$ solution of carbamide peroxide, on the permeability and surface morphology of enamel is reported. The investigation was carried out on replicas of incisors obtained after different treatment times and for several patients, employing scanning electron microscopy to study the morphological features of the treated teeth. The significance of the analytical study was corroborated by a statistical analysis of the results. The collected data suggest that hydrogen peroxide treatment increases the enamel permeability, and this could be related with tooth sensitivity, whereas the carbamide peroxide solution increases the formation of precipitates on the tooth enamel.
\end{abstract}

Keywords: hydrogen peroxide; carbamide peroxide; enamel; polyether replicas; scanning electron microscopy; tooth sensitivity

\section{Introduction}

Tooth bleaching (also referred as whitening) of vital teeth has a major aesthetic and psychological impact on dental practice and offers a conservative treatment option in the management of discoloured teeth [1]. In-office bleaching procedures are usually employed in the case of severe discoloration or when a rapid treatment is desired [2].

In-office bleaching is usually performed with high concentration of hydrogen peroxide $\left(\mathrm{H}_{2} \mathrm{O}_{2}, 30-35\right.$ wt.\%) [2,3] and of carbamide peroxide (35-40 wt.\%) [4,5]. Two bleaching mechanisms have been proposed. One suggests that peroxides cause slight morphologic alterations in the enamel (oxidizing organic matrix into an opaque whiter material), which reduce its translucency by scattering light, so that the ensuing opaqueness masks the subjacent dentin layer (frosted-glass effect) [6-11]. The other one proposes that hydrogen peroxide, with a high oxidative power, may dissociate into water, oxygen, and some free radical species, such as hydroxyl radicals $(\mathrm{HO} \cdot)$, that are capable of degrading complex longchain organic chromophore molecules, which are responsible for tooth discoloration [2,10].

The question about the adverse effects of tooth whitening on the enamel and dentin is still debated and several studies in the literature reported controversial results. Surface micro-hardness tests and variable pressure scanning electron microscope (SEM) analyses have shown no deleterious effect on the enamel surface, and confocal laser scanning microscopy results have confirmed the hydrogen peroxide bleaching safety on the enamel surface and subsurface [12]. Raman spectroscopy analyses have demonstrated no changes in the enamel micro-chemical composition [12]. On the other hand, a decrease in enamel 
and dentin micro-hardness $[2,13,14]$ and changes in enamel surface morphology $[2,15]$ and structure [16] are also reported.

Differences between these published reports may arise from a variation in the concentration of the chemical bleaching agents. For example, a concentration of $35 \mathrm{wt} . \%$ carbamide peroxide (usually, 11-12\% $\mathrm{H}_{2} \mathrm{O}_{2}$ ) affects the structure of enamel, whereas solutions of $10 \mathrm{wt} . \%$ or $16 \mathrm{wt} . \%$ have no effect [17]. The adverse effects could be also associated to $\mathrm{pH}$ value and oxidative effects of bleaching agents [3]. Furthermore, as enamel is composed mostly of hydroxylapatite crystals, different mineral surfaces exposed to the environment may also have a role in this variability. In fact, for the sake of an example, the (001) and (010) faces of hydroxylapatite are characterized by different surface properties and reactivity $[18,19]$, which could be exploited, for example, by devising specific biomaterials for dental applications [20].

The evaluation of enamel permeability has been previously performed by some authors both in vivo and in vitro. Changes in permeability are correlated to physiological $[21,22]$ and post-treatment variations, such as topical fluoride applications and etching treatment $[23,24]$, by means of the SEM inspection of polyether enamel replicas. For this procedure, impressions of enamel surfaces are carried out with vinyl polyxiloxane, and replicas are then obtained using a polyether impression material. This technique uses droplet formation to display the discharge of liquid from the enamel during the setting time of the hydrophobic vinyl polyxiloxane impression material, and yields an in situ morphological image of the outward fluid flow through the tooth enamel [21].

The aim of this study was to evaluate the in vivo changes in the enamel surface produced by $35 \%$ hydrogen peroxide and $30 \%$ carbamide peroxide in-office application to mature permanent teeth through scanning electron microscopy (SEM) inspection of the sequential replicas made in vivo. The tested null hypothesis was that bleaching treatment did not affect the enamel permeability in vivo.

\section{Materials and Methods}

\subsection{Materials}

Eighty permanent sound upper central incisors from 40 subjects aged 25-42 years, attended at the Department of Oral Sciences of the University of Bologna for dental care, were selected. All the subjects enrolled in the study gave their informed consent to the bleaching procedures.

The study has been conducted in full accordance with the ethical principles of the World Medical Association Declaration of Helsinki. All subjects included in the study gave written informed consent to the procedure, which was non-invasive, and did not create any risk for the patients.

All the patients enrolled in the study completed the health history form and received a complete oral exam to verify the absence of dental caries, prostheses, periodontal disease, and the presence of a normal saliva flow. Exclusion criteria included: previous bleaching treatment, self-reported sensitivity, intrinsic staining, caries or restorations on upper incisors and canine, pregnancy, smoking, orthodontic appliance and other pre-existing medical or dental conditions that could increase the procedure risk.

Two weeks before starting treatments a run-in period was performed by all the subjects enrolled in the study to standardize toothbrush (Oral-B Classic Care ${ }^{\mathrm{TM}}$, Procter and Gamble, Cincinnati, USA) with a 1400 ppm fluoride dentifrice (Elmex Protezione Carie, Gaba, Therwil, Switzerland). During the entire duration of the study patients were asked to avoid darkened food and beverage, and the use of rinses and toothpaste containing chlorhexidine and other mouthrinses.

Two different treatments were devised, the first one using a $35 \mathrm{wt} . \%$ hydrogen peroxide solution (Pola Office, SDI, Melbourne, Vic., Australia), the second one employing a 30\% carbamide peroxide gel (Vivastyle ${ }^{\circledR}$, Vivadent, Schaan, Liechtenstein). Both the treatments were performed under a liquid dam (OpalDam, Ultradent, Soth Jordan, UT, USA) following the instructions as recommended by the manufacturers (see Table 1). For the sake of 
simplicity, the treatments with hydrogen peroxide and carbamide peroxide were labelled as $\mathrm{HP}$ and $\mathrm{CP}$, respectively.

Table 1. Bleaching agent compositions.

\begin{tabular}{cl}
\hline Bleaching Agents & \multicolumn{1}{c}{ Composition } \\
\hline Pola Office 35\% & $\begin{array}{l}\text { Liquid: 35\% hydrogen peroxide, distilled water, and stabilizers. } \\
\text { Powder: thickener, catalyst, pigments, and potassium nitrate. } \mathrm{pH} \sim 7 .\end{array}$ \\
\hline Vivastyle & $\begin{array}{l}\text { Gel ready-for-use: glycerine, aqua, urea peroxide, potassium nitrate, } \\
\text { carbomer, sodium hydroxide, disodium EDTA, and flavour. Active } \\
\text { ingredients: 30\% carbamide peroxide. }\end{array}$ \\
\hline
\end{tabular}

The 40 patients were randomly subdivided in two groups of 20 members $(n=20$, each). The first group was assigned to the HP treatment and the second one to the $\mathrm{CP}$ bleaching agent. For the purpose of the present study, the following three sampling times (impressions, vide infra) were considered: (1) T0 sampling, which was performed before any tooth bleaching treatment; (2) T1 sampling, carried after the first treatment of either $\mathrm{HP}$ of CP; and (3) T2 sampling, performed after a second and final treatment with the bleaching agent.

The period between treatment $\mathrm{T} 1$ and treatment $\mathrm{T} 2$ was 1 week. After each treatment, the patients were dismissed and asked to return after $30 \mathrm{~min}$. During this time, the patients could only drink water. When they returned, both of the incisors were impressed.

At the end of the study, each patient, after the last impression, received a prophylaxis acidulate phosphate fluoride application.

\subsection{Replica Technique}

The method used to investigate the morphology of enamel, by detecting the presence of droplets, has been described previously [21,23].

Replicas were sequentially obtained in the central incisors in order to study the surface morphology and permeability changes of the enamel after the bleaching treatments. The replica technique yielded qualitative and quantitative findings on outward fluid flow on tooth enamel surfaces using droplet formation, during the setting time of the impression material, in order to display the discharge of liquid from the enamel.

Before taking each impression, each tooth was professionally brushed with a prophylactic brush (Prophy minicups, Westpoint-Perident, Firenze, Italy) mounted on a rotary micromotor handpiece $(4000 \mathrm{rpm})$ for $30 \mathrm{~s}$ with a pressure adequate to bend brush bristles, and was finally air-dried for $10 \mathrm{~s}$. The impressions of the buccal surface of the central incisors were made using polyvinylsiloxane (Affinis light body; Coltene, Altstätten, Switzerland). The material was allowed to set for $5 \mathrm{~min}$. Then, the impression was removed from the enamel surface and was later cast in a polyether impression material (Permadyne Garant; 3 M ESPE, St. Paul, MN, USA). After separation, the casts were gold-sputtered and inspected by scanning electron microscopy (Model 5400, JEOL; Tokyo, Japan).

\subsection{Evaluation of Tooth Permeability and Statistical Analysis}

For each sample (replica of the incisors), two operators independently collected a representative area of $60 \times 45 \mu \mathrm{m}^{2}$ each, by randomly examining the enamel surface at $\times 2000$ magnification. From this double-blind protocol, each operator collected the number of droplets on the investigated area and normalized the value to $1000 \mu \mathrm{m}^{2}$. Then, the mean value of the normalized number of droplets was recorded and subsequently employed for the statistical analysis. ANOVA for repeated measures with a split-plot design was performed to evaluate the differences between treatments, time-related variations in the number of droplets, and the interaction between treatments and time-related variations in the number of droplets. For the statistical evaluation, the samples collected before any treatment (T0, vide supra) were considered as the control group in order to assess the variation of enamel permeability. 


\subsection{Evaluation of Tooth Sensitivity}

A calibrated examiner who was blinded about the study groups recorded tooth sensitivity perceived by the patient by deploying a blast of air to teeth isolated with cotton rolls, from a distance of $1.0 \mathrm{~cm}$ for $1 \mathrm{~s}$, as per the American Dental Association recommended guidelines [25], at the second appointment after the second treatment. Sceffe's scale was used for the measurement of sensitivity [26]: $0=$ absence of pain, but perceiving stimulus; 1 = slight pain (mild sensitivity); 2 = pain during the application of stimulus (moderate sensitivity); and 3 = pain during the application of stimulus and immediately thereafter (severe sensitivity).

\section{Results}

\subsection{SEM Analysis}

A morphological analysis of the representative areas of the incisor replicas was performed before and after the treatments. Typical examples of SEM images at T0 (baseline), $\mathrm{T} 1$, and $\mathrm{T} 2$ are reported in Figures 1 and 2 for patients treated with hydrogen peroxide (HP) and carbamide peroxide $(\mathrm{CP})$, respectively.

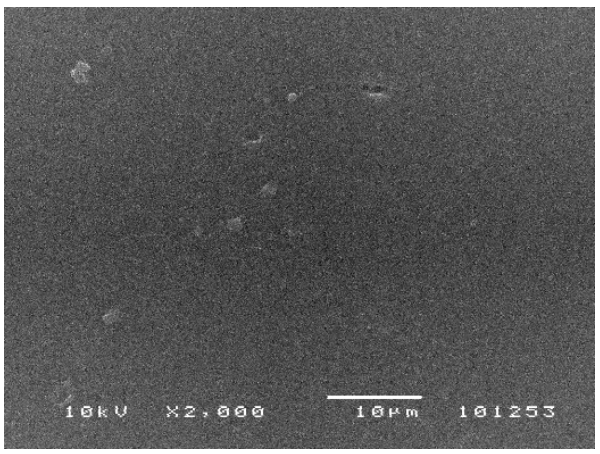

(a)

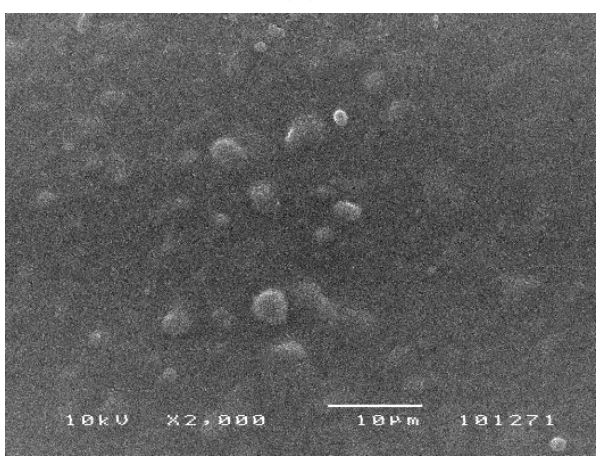

(c)

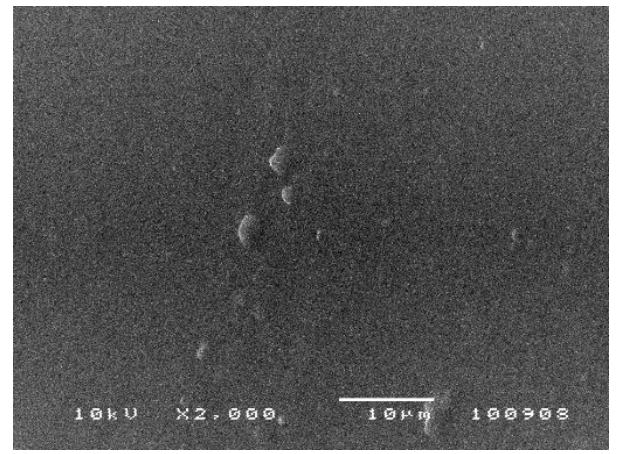

(b)

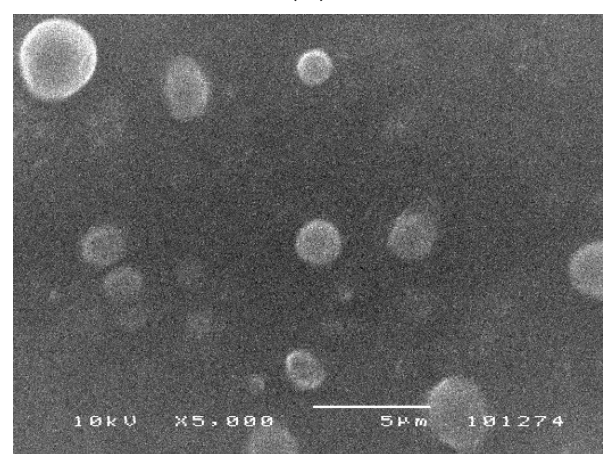

(d)

Figure 1. SEM pictures $(\times 2000)$ of a typical sample of incisor replicas from the group of patients treated with hydrogen peroxide (HP Group). Compared with the physiological permeability highlighted at (a) baseline, the replicas relating to the two experimental times (T1 and T2) show variation in the (b) permeability of enamel with a relative increase of number and diameter of droplets at $\mathrm{T} 1$ and (c) a substantial increase in the permeability of the enamel, with large and numerous droplets covering the entire enamel surface at T2. In $(\mathbf{d})$, a higher magnification $(\times 5000)$ of the large fluid droplets is reported. 


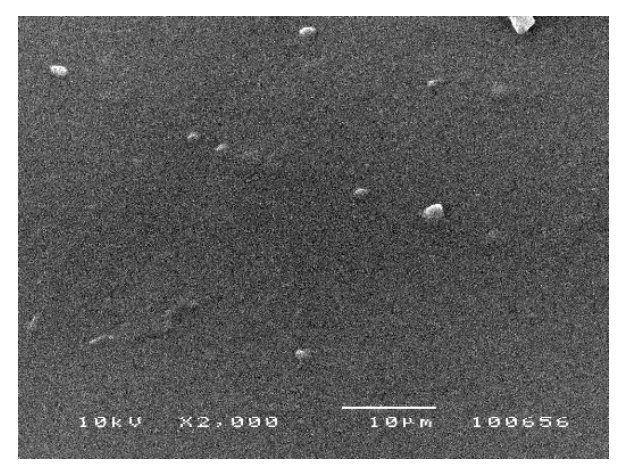

(a)

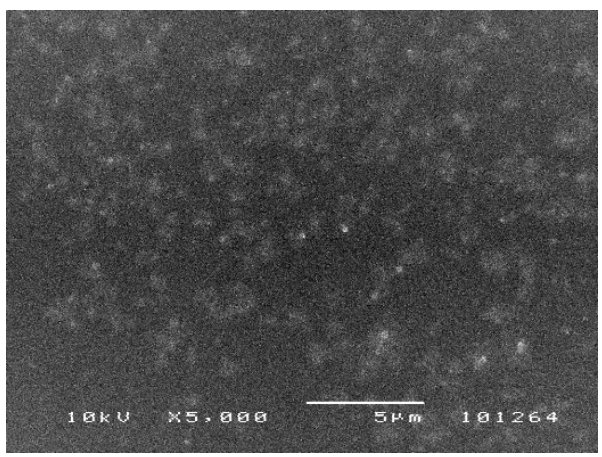

(c)

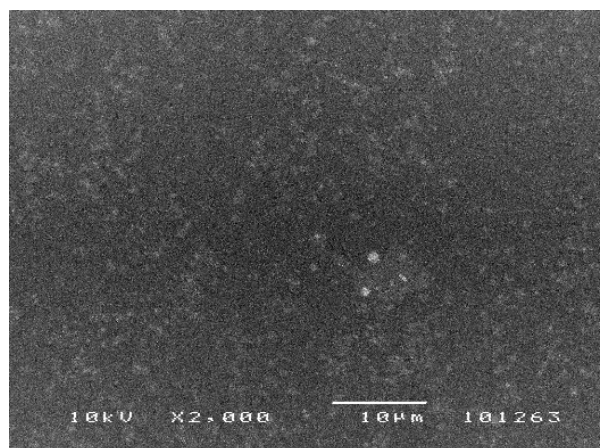

(b)

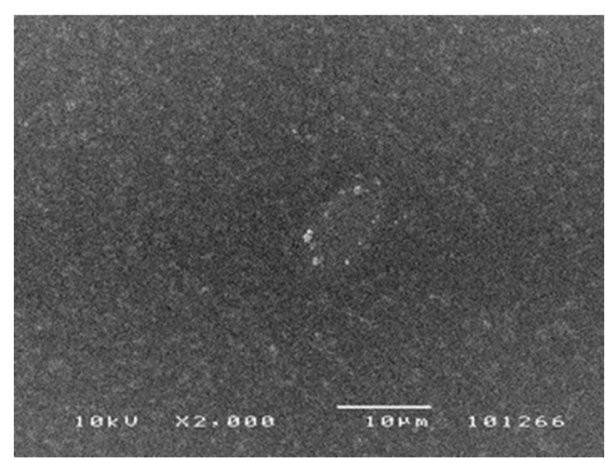

(d)

Figure 2. SEM pictures $(\times 2000)$ of a typical sample of incisor replicas from the group of patients treated with carbamide peroxide (CP Group). Compared with the physiological permeability highlighted at (a) baseline, the replicas related to (b) Table 1 and (c) T2 show no increase in permeability, with no droplets detectable even at (d) higher magnifications. In all of the samples, the treatment involved the deposition of precipitates covering the entire enamel surface $(\mathbf{b}-\mathbf{d})$ in the absence of fluid release.

The baseline replicas for both groups of patients showed the presence of a few microscopic droplets on the enamel surfaces, which represent outward fluid flow from enamel during the setting time of the material arranged accordingly with a previous study [21]. Figures $1 \mathrm{a}$ and $2 \mathrm{a}$ report, as an example, two representative SEM micrographs with areas of $60 \times 45 \mu \mathrm{m}^{2}$ of the baseline replicas for patients treated with HP and CP, respectively. Not many droplets (bright circular features) are here visible at the surface, with a diameter up to about $2 \mu \mathrm{m}$.

After the first treatment (T1), the replicas of some HP-treated samples revealed an increase in the number of fluid droplets on the enamel surface (Figure 1b). In addition, the size (diameter) of these droplets was larger than those observed on the baseline replicas, suggesting an increased fluid flow. Figure $1 \mathrm{~b}$ shows an SEM micrograph of the replica surfaces of the HP-treated (T1) samples. In comparison with the baseline replica, several droplets were observed with a diameter greater than $2 \mu \mathrm{m}$. Instead, samples treated at T1 with CP showed a deposition of precipitates, covering almost the entire surface, with almost no detectable fluid droplets. Figure $2 \mathrm{~b}$ reports an SEM micrograph that indicates a completely different behaviour with respect to the post-treatment (T1) morphology of Figure $1 b$. In Figure 2b, bright spots/zones with irregular boundaries are associated with diffuse precipitates, typically less than $1 \mu \mathrm{m}$ in lateral size.

The SEM inspection of replicas obtained $30 \mathrm{~min}$ after the second treatment (T2) of incisors treated with 35\% hydrogen peroxide solution showed a massive permeability of the enamel, with fluid droplets all over the samples. In addition, the size (diameter) of these droplets was larger than those observed on the baseline and T1 replicas, suggesting an increased fluid flow. Figure 1c shows an example of a high coverage of droplets, whose 
diameter is up to more than $5 \mu \mathrm{m}$, whereas Figure $1 \mathrm{~d}$ is a higher resolution SEM image, which better highlights the droplets morphology.

Conversely, the second treatment with carbamide peroxide (T2) produced a surface almost free of droplets and characterized by the presence of ubiquitously diffused precipitates (see Figure 2c and the higher resolution image of Figure 2d).

Thus, the bleaching treatment with a 35\% solution of hydrogen peroxide involved, especially at T2, an increase in enamel permeability, whereas using a 30\% solution of carbamide peroxide for the treatment resulted in the formation of precipitates at the enamel surface, suggesting the absence of possible adverse effects in terms of enamel fluid release.

\subsection{Statistical Analysis}

From the statistical analysis, relating the number of droplets to three predictive values (treatment, time, and the interaction between treatment and time), several conclusions could be drawn.

First, a post-hoc Tukey's test was performed to assess the absence of statistical differences between the baseline replicas, i.e., before any treatment (T0). The calculated $p=0.09>0.05$ meant that the two paired samples were not significantly different, and the enamel morphological and permeability features were considered to be similar between the two groups of 20 patients each.

Then, one-way ANOVA for repeated measures followed by a pairwise t-test was performed for both the HP and $\mathrm{CP}$ groups. A graphical representation of the data is reported in Figure 3, whereas a summary of the t-tests is reported in Table 2. Prior the treatments, the incisors in the two groups of patience have a similar permeability, within one standard deviation ( $1 \sigma$; confidence interval of about $95 \%)$, in agreement with the Tukey's test. The treatments with CP and HP had different statistical behaviours. In fact, with respect to the baseline, the mean number of droplets increased when using the hydrogen peroxide bleaching agent, but the same number decreased when employing carbamide peroxide. The t-tests (Table 2) showed that, by using the HP solution, there was no significant difference between the baseline (T0) and the first treatment (T1), as highlighted by $p=0.21>0.05$. Only the second treatment statistically affected the number of droplets found on the enamel surface $(p<0.05)$. Regarding the CP treatment, the reduction in enamel permeability was visible after the first treatment $(p<0.05)$, but there was not a statistical difference in the number of droplets between the first (T1) and the second (T2) applications of carbamide peroxide $(p=0.38>0.05)$.
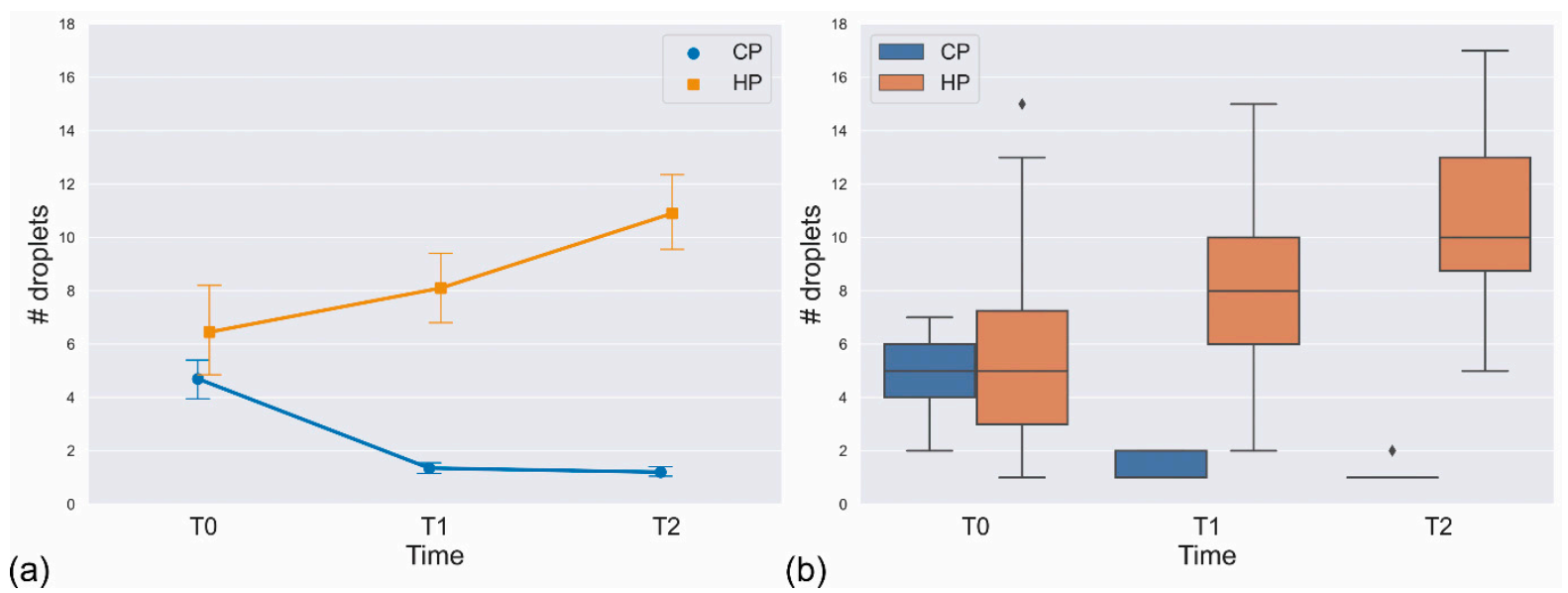

Figure 3. (a) Mean scores (number of droplets normalized to an area of $1000 \mu \mathrm{m}^{2}$ ) at different treatment times for the group treated with carbamide peroxide (CP) and the group treated with hydrogen peroxide (HP). The vertical bars represent the standard deviations calculated at each point. (b) Box plot representation of the dispersion of the data. 
Table 2. Pairwise t-tests performed for both the hydrogen peroxide $(\mathrm{HP} ; n=20)$ and carbamide peroxide $(\mathrm{CP} ; n=20)$ groups of treatments. A and B represent different treatment times $(\mathrm{T} 0, \mathrm{~T} 1$, and $\mathrm{T} 2), \sigma$ is the variance, and $\mathrm{df}$ is the degrees of freedom $(n-1)$.

\begin{tabular}{|c|c|c|c|c|c|c|c|c|}
\hline $\mathbf{A}$ & B & $\operatorname{mean}(\mathrm{A})$ & $\sigma(\mathbf{A})$ & mean $(B)$ & $\sigma(\mathrm{B})$ & $\mathbf{T}$ & df & $p$ \\
\hline \multicolumn{9}{|c|}{ HP group } \\
\hline T0 & T1 & 6.45 & 4.148 & 8.10 & 3.194 & -1.313 & 19 & $2.050 \times 10^{-1}$ \\
\hline T0 & $\mathrm{T} 2$ & 6.45 & 4.148 & 10.90 & 3.275 & -4.783 & 19 & $1.290 \times 10^{-4}$ \\
\hline $\mathrm{T} 1$ & $\mathrm{~T} 2$ & 8.10 & 3.194 & 10.90 & 3.275 & -4.729 & 19 & $1.460 \times 10^{-4}$ \\
\hline \multicolumn{9}{|c|}{ CP group } \\
\hline T0 & $\mathrm{T} 1$ & 4.70 & 1.658 & 1.35 & 0.489 & 9.571 & 19 & $1.061 \times 10^{-8}$ \\
\hline T0 & $\mathrm{T} 2$ & 4.70 & 1.658 & 1.20 & 0.410 & 9.200 & 19 & $1.982 \times 10^{-8}$ \\
\hline $\mathrm{T} 1$ & $\mathrm{~T} 2$ & 1.35 & 0.489 & 1.20 & 0.410 & 0.900 & 19 & $3.793 \times 10^{-1}$ \\
\hline
\end{tabular}

In addition, the variance within the time calculated for HP was homogeneous (Levene's test; $p=0.77)$, whereas no homoscedasticity was observed for the treatment with $\mathrm{CP}$. These results suggest that the solution of $30 \mathrm{wt} . \%$ of carbamide peroxide gave more reproducible results, independently of the dental physiology of the patient. Instead, the treatment with $35 \mathrm{wt} . \%$ hydrogen peroxide solution was more prone to variability in terms of the generated droplets on the enamel surface. This is also well highlighted by the box plot reported in Figure 3b, which shows the dispersion of the data.

Thus, the statistical analysis allowed for rejecting the null hypothesis: both HP and CP treatments resulted in $p$ values much lower than 0.05 , meaning that both solutions affected the enamel permeability.

A post hoc power analysis, performed using the G*Power software [27], of the present statistical protocol resulted in a power of 0.99999998 within the group of patients treated with either $\mathrm{HP}$ or $\mathrm{CP}$, confirming the quality of the present data.

\subsection{Tooth Sensitivity}

The majority of patients experienced mild to moderate sensitivity (1-3 on the Sceffe's scale), as shown in Table 3. Twenty-five percent of participants from the CP group reported no post-operative sensitivity. Twenty percent of the HP group and $50 \%$ of the $\mathrm{CP}$ group experienced mild tooth sensitivity, $50 \%(\mathrm{HP})$ and $25 \%(\mathrm{CP})$ reported moderate sensitivity, and six patients (30\%) from the HP group reported severe sensitivity and required treatment with supplemental 3\% potassium nitrate gel (Ultra EZ ${ }^{\circledR}$, Ultradent Products Inc., South Jordan, UT, USA).

Table 3. Tooth sensitivity after bleaching treatment (Sceffe's scale).

\begin{tabular}{ccccc}
\hline & Absent & Mild & Moderate & Severe \\
\cline { 2 - 5 } & $\boldsymbol{n} \%$ & $\boldsymbol{n} \%$ & $\boldsymbol{n} \%$ & $\boldsymbol{n} \%$ \\
\hline $35 \%$ HP $(n=20)$ & 0 & $4-20$ & $10-50$ & $6-30$ \\
$30 \%$ CP $(n=20)$ & $5-25$ & $10-50$ & $5-25$ & 00 \\
Total $(n=40)$ & $5-12.5$ & $14-35$ & $15-37$ & $6-15$ \\
\hline
\end{tabular}

No HP-treated patient experienced a non-sensitive condition and, on the contrary, in the $\mathrm{CP}$-treated group, no patient experienced severe hypersensitivity. However, the results of the study allowed us to hypothesize a correlation between the whitening agent, enamel permeability, and sensitivity. HP treatment could be associated with a greater permeability of the enamel, especially at $\mathrm{T} 2$, and more severe post-treatment hypersensitivity. The treatment with $\mathrm{CP}$ appeared to be associated with the deposition of precipitates and a decrease in the permeability of the enamel, with no statistically significant differences between $\mathrm{T} 1$ and $\mathrm{T} 2$, with less hypersensitivity after treatment. 


\section{Discussion}

Tooth sensitivity is the main side-effect of vital bleaching treatment and, in clinical research studies, its occurrence during bleaching procedures is reported in a range of $18-78 \%$ of patients [28,29]. This side-effect is attributed to the small, microscopic enamel defects and subsurface pores, as well as the rapid transenamel and transdentinal diffusion of hydrogen peroxide to the pulp or other toxic components released with the degradation of the bleaching gels [25].

To the authors' knowledge, no study in the literature has investigated the possible correlation between enamel permeability and whitening treatment. The present study allows for relating the qualitative and quantitative evaluation of the permeability of the enamel with post-operative sensitivity.

According to the performed experimental and statistical analyses, the null hypothesis of the present study must be rejected. In fact, both hydrogen peroxide and carbamide peroxide bleaching agents produced changes in the permeability of the enamel. The literature search revealed no studies that evaluated the effects of whitening treatments on enamel permeability. The replica technique employed, which is non-invasive and risk-free for the patient, allows for evaluating the effect of these treatments in vivo. This technique provided qualitative and quantitative findings on outward fluid flow on tooth enamel surfaces visualized as fluid droplet formation, resulting from the discharge of liquid from enamel during the setting time of the impression material. The fluid forming these droplets may come from free, unbound water in blind outer enamel porosities and partly in deeper structures. Presumably, the mechanism of droplet formation is simply diffusion. When a water-free impression material is applied to hydrated enamel, water diffuses out of the enamel down its concentration gradient and accumulates over the pores, without wetting or spreading, on the light-bodied hydrophobic material [21]. Different treatments, such as topical fluoride application or acid etching, affect enamel permeability, modifying surface droplets formation [23,24]. The changes in enamel fluid release could be related to post-treatment sensitivity. The preliminary results obtained allow for us to hypothesize the effect of both hydrogen and carbamide peroxide on the permeability of the enamel; in particular, treatment with hydrogen peroxide seems, especially after the second application, to involve a considerable increase in the release of fluids from the enamel surface. This effect may be clinically correlated to the moderate/severe post treatment sensitivity reported by most patients from the HP group. On the other hand, treatment with carbamide peroxide showed a reduction in permeability associated with a lower post-operative sensitivity. These preliminary results agree with the available data in the literature, confirming a greater post-operative sensitivity associated with the use of high (30-35 wt.\%) concentrations of hydrogen peroxide [30]. it is likely that this effect is caused by a very fast passage of HP through the dental structure, i.e., within $15 \mathrm{~min}$ after application, so larger amounts of reactive species may arrive to the pulp, leading to a more intense inflammatory response and tooth sensitivity [31]. Our results support a role of bleaching treatments in enamel permeability changes, which could be involved in post-operative sensitivity, although additional mechanisms cannot be excluded.

Further studies will be necessary in order to confirm this hypothesis. Oral health professionals should carefully select the type, concentration of the bleaching agent, and whitening procedure (i.e., in-office, at-home, light-activated bleaching system, and not) and should offer proper instructions to prevent and treat sensitivity. From this perspective, the present results show that the topical application of fluoride can reduce the adverse post-operative sensitivity effects due to treatments with high concentrations of hydrogen peroxide. In fact, this component is important for reducing the permeability of the enamel, as also reported in previous works [23].

\section{Conclusions}

The present in vivo study employed the replica technique to investigate enamel permeability after $35 \%$ hydrogen peroxide and $30 \%$ carbamide peroxide applications. Perme- 
ability changes were correlated with patients' post-operative sensitivity. This side-effect is attributed to the rapid transenamel and transdentinal diffusion of hydrogen peroxide to the pulp. As the diffusion rate of ions and molecules, and fluid flowing through the enamel are related to permeability, the latter could be involved in the pathogenesis of post-whitening tooth sensitivity. The results of this study showed that an increase in the permeability of enamel as displayed after treatment with $35 \%$ hydrogen peroxide was associated with a moderate/severe post treatment sensitivity. The whitening agent should be effective and minimize the adverse clinical effects of the treatment, in particular dental hypersensitivity. Additional strategies for reducing enamel permeability, such as topical fluoride treatment, can help to control this adverse effect.

Author Contributions: Conceptualization, G.V., S.C., and A.B.; methodology, A.B. and S.C. (bleaching treatments, replicas, and tooth sensitivity), G.U., D.M., and G.V. (SEM and statistical analysis); validation, G.V., S.C., D.M., A.B., and G.U.; formal analysis, G.V., S.C., D.M., A.B., and G.U.; investigation, G.V., S.C., D.M., A.B., and G.U.; data curation, G.V., S.C., D.M., A.B., and G.U.; writing-original draft preparation, G.V., S.C., D.M., A.B., and G.U.; writing—review and editing, G.V., S.C., D.M., A.B., and G.U.; visualization, G.V., S.C., D.M., A.B., and G.U.; supervision, G.V., S.C., and A.B. All of the authors have read and agreed to the published version of the manuscript.

Funding: The authors received no funding for this work.

Conflicts of Interest: The authors declare no conflict of interest.

\section{References}

1. Blankenau, R.; Goldstein, R.E.; Haywood, V.B. The current status of vital tooth whitening techniques. Compend. Contin. Educ. Dent. 1999, 20, 781-784. [PubMed]

2. Dias Ribeiro, A.P.; Sacono, N.T.; Lessa, F.C.; Nogueira, I.; Coldebella, C.R.; Hebling, J.; de Souza Costa, C.A. Cytotoxic effect of a $35 \%$ hydrogen peroxide blesching gel on odonto blast-like MDPC-23 cells. Oral Surg. Oral Med. Oral Pathol. Oral Radiol. Endod. 2009, 108, 458-464. [CrossRef]

3. Sun, L.; Liang, S.; Sa, Y.; Wang, Z.; Ma, X.; Jiang, T.; Wang, Y. Surface alteration of human tooth enamel subjected to acidic and neutral 30\% hydrogen peroxide. J. Dent. 2011, 39, 686-692. [CrossRef]

4. Goldberg, M.; Grootveld, M.; Lynch, E. Undesiderable and adverse effects of tooth whitening products: A review. Clin. Oral Investig. 2010, 14, 1-10. [CrossRef]

5. Dahl, J.E.; Pallesen, U. Tooth bleaching-A critical review of the biological aspects. Crit. Rev. Oral Biol. Med. 2003, 14, $292-304$. [CrossRef]

6. Cavalli, V.; Arrais, C.A.; Giannini, M.; Ambrosano, G.M. High-concentrated carbamide peroxide bleaching agents effects on enamel surface. J. Oral Rehabil. 2004, 31, 155-159. [CrossRef]

7. Pinto, C.F.; Oliveira, R.; Cavalli, V.; Giannini, M. Peroxide bleaching agent effects on enamel surface microhardness, roughness and morphology. Braz. Oral Res. 2004, 18, 306-311. [CrossRef]

8. Fu, B.; Hoth-Hannig, W.; Hannig, M. Effects of dental bleaching on micro- and nano-morphological alterations of the enamel surface. Am. J. Dent. 2007, 20, 35-40.

9. Markovic, L.; Jordan, R.A.; Lakota, N.; Gaengler, P. Micromorphology of enamel surface after vital tooth bleaching. J. Endod. 2007, 33, 607-610. [CrossRef]

10. Ushigome, T.; Takemoto, S.; Hattori, M.; Yoshinari, M.; Kawada, E.; Oda, Y. Influence of peroxide treatment on bovine enamel surface-Cross-sectional analysis. Dent. Mater. J. 2009, 28, 315-323. [CrossRef]

11. Eimar, H.; Siciliano, R.; Abdallah, M.N.; Nader, S.A.; Amin, W.M.; Martinez, P.P.; Celemin, A.; Cerruti, M.; Tamimi, F. Hydrogen peroxide whitens teeth by oxidizing the organic structure. J. Dent. 2012, 40 (Suppl. S2), e25-e33. [CrossRef]

12. Götz, H.; Duschner, H.; White, D.J.; Klukowska, A. Effects of elevated hydrogen peroxide strip bleaching on surface and subsurface enamel including subsurface histomorphology, micro-chemical composition and fluorescence changes. J. Dent. 2007, 35, 457-466. [CrossRef]

13. Lewistein, I.; Hirschfeld, Z.; Stabholz, A.; Rostein, I. Effect of hydrogen peroxide and sodium perborate on the microhardness of human enamel and dentin. J. Endod. 1994, 20, 61-63. [CrossRef]

14. Attin, T.; Kocabiyik, K.; Buchalla, W.; Hanning, C.; Becker, K. Susceptibility of enamel surfaces to demineralization after application of fluoridated carbamide peroxide gels. Caries Res. 2003, 37, 93-99. [CrossRef]

15. Kwamoto, K.; Tsujimoto, Y. Effects of the hydroxyl radical and hydrogen peroxide on tooth bleaching. J. Endod. 2004, 30, 45-50. [CrossRef]

16. Ruse, N.D.; Smith, D.C.; Torneck, C.D.; Titley, K.C. Preliminary surface analysis of etched, bleached, and normal bovine enamel. J. Dent. Res. 1990, 69, 1610-1613. [CrossRef] 
17. Oltu, Ü.; Gürgan, S. Effects of three concentrations of carbamide peroxide on the structure of enamel. J. Oral Rehabil. 2000, 27, 332-340. [CrossRef] [PubMed]

18. Canepa, P.; Chiatti, F.; Corno, M.; Sakhno, Y.; Martra, G.; Ugliengo, P. Affinity of hydroxyapatite (001) and (010) surfaces to formic and alendronic acids: A quantum-mechanical and infrared study. Phys. Chem. Chem. Phys. 2011, 13, 1099-1111. [CrossRef]

19. Ulian, G.; Moro, D.; Valdrè, G. First-principles study of structural and surface properties of (001) and (010) surfaces of hydroxylapatite and carbonated hydroxylapatite. J. Appl. Cryst. 2016, 49, 1893-1903. [CrossRef]

20. Bertacci, A.; Moro, D.; Ulian, G.; Valdre, G. Development of A Nano-Apatite Based Composite Sealer for Endodontic Root Canal Filling. J. Compos. Sci. 2021, 5, 30. [CrossRef]

21. Bertacci, A.; Chersoni, S.; Davidson, C.L.; Prati, C. In vivo enamel fluid movement. Eur. J. Oral Sci. 2007, 115, 169-173. [CrossRef]

22. Lucchese, A.; Bertacci, A.; Chersoni, S.; Portelli, M. Primary enamel permeability: A SEM evaluation in vivo. Eur. J. Paediatr. Dent. 2012, 13, 231-235. [PubMed]

23. Chersoni, S.; Bertacci, A.; Pashley, D.H.; Tay, F.R.; Montebugnoli, L.; Prati, C. In vivo effects of fluoride on enamel permeability. Clin Oral Investig. 2011, 15, 443-449. [CrossRef] [PubMed]

24. Bertacci, A.; Lucchese, A.; Taddei, P.; Gherlone, E.F.; Chersoni, S. Enamel structural changes induced by hydrochloric and phosphoric acid treatment. J. Appl. Biomater. Funct. Mater. 2014, 12, 240-247. [CrossRef] [PubMed]

25. Nanjundasetty, J.K.; Ashrafulla, M. Efficacy of desensitizing agents on postoperative sensitivity following an in-office vital tooth bleaching: A randomized controlled clinical trial. J. Conserv. Dent. 2016, 19, 207-211. [CrossRef] [PubMed]

26. Gunjikar, T.; Chute, M.; Lobo, T.; Pol, D.S.; Pol, G.D. Methods for the evaluation of the pain associated with dentinal hypersensitivity. JIDA 2012, 6, 57-59.

27. Faul, F.; Erdfelder, E.; Lang, A.-G.; Buchner, A. G*Power 3: A flexible statistical power analysis program for the social, behavioral, and biomedical sciences. Behav. Res. Methods 2007, 39, 175-191. [CrossRef]

28. He, L.B.; Shao, M.Y.; Tan, K.; Xu, X.; Li, J.Y. The effects of light on bleaching and tooth sensitivity during in-office vital bleaching: A systematic review and meta-analysis. J. Dent. 2012, 40, 644-653. [CrossRef]

29. Kothari, S.; Gray, A.R.; Lyons, K.; Tan, X.W.; Brunton, P.A. Vital bleaching and oral-health-related quality of life in adults: A systematic review and meta-analysis. J. Dent. 2019, 84, 22-29. [CrossRef]

30. Mounika, A.; Mandava, J.; Roopesh, B.; Karri, G. Clinical evaluation of colour change and tooth sensitivity with in-office and home bleaching treatments. Indian J. Dent. Res. 2018, 29, 423-427. [CrossRef]

31. Cooper, J.S.; Bokmeyer, T.J.; Bowles, W.H. Penetration of the pulp chamber by carbamide peroxide bleaching agents. J. Endod. 1992, 18, 315-317. [CrossRef] 